African Journal of Microbiology Research Vol. 7(2), pp. 130-136, 8 January, 2013

Available online at http://www.academicjournals.org/AJMR

DOI: $10.5897 / A J M R 12.1563$

ISSN 1996-0808 @2013 Academic Journals

Full Length Research Paper

\title{
Plasmid mediated transfer of antibiotic resistance and heavy metal tolerance in thermotolerant water borne coliforms
}

\author{
Suman Tewari ${ }^{1}$, Pramod W Ramteke ${ }^{2}$, Manikant Tripathi ${ }^{3}$, Shailendra Kumar ${ }^{3}$ and \\ Satyendra Kumar Garg ${ }^{3 *}$ \\ ${ }^{1}$ Environmental Microbiology Section, Indian Institute of Toxicology Research, Lucknow, India. \\ ${ }^{2}$ Department of Biological Sciences, Sam Higginbottom Institute of Agriculture, Technology and Sciences, \\ Allahabad, India. \\ ${ }^{3}$ Centre of Excellence, DST-FIST Supported Department of Microbiology, Dr. Ram Manohar Lohia Avadh University, \\ Faizabad, India. \\ Accepted 9 January, 2013
}

\begin{abstract}
The antibiotic resistance and heavy metal tolerance pattern of 201 water borne thermotolerant coliforms isolated from rural areas were studied. Most of the isolates exhibited resistance to one or more antibiotics under study, and expressed tolerance to multiple metals. Twenty four strains representing different resistance combinations were tested for plasmid transfer to Escherichia coli K-12 recipient strain. Plasmid transfer was detected in all 24 strains studied for conjugation. Among antimicrobials bacitracin, ampicillin, and among metals nickel, copper, cadmium, cobalt, chromium and arsenic resistances were transferred most frequently. Linked transfer of antibiotics and metals was demonstrated in 12 strains. Thirty two cultures of thermotolerant coliforms were studied for R-plasmid curing using acridine orange. Among antibiotics, curing of resistance was observed for streptomycin, cephaloridine and kanamycin. Curing of resistance to nickel, copper, mercury, chromium, copper and arsenic were also observed. The potential health risk of plasmid mediated resistances to antibiotics and metal ions in coliforms isolated from rural drinking water sources is discussed.
\end{abstract}

Key words: Thermo-tolerant coliforms, R-plasmids, conjugation transfer, resistance transfer.

\section{INTRODUCTION}

Thermo-tolerant coliforms is an indicator group of fecal coliforms, which has all the properties of total coliforms, and also capable to ferment lactose with the production of acid and gas in $24 \mathrm{~h}$ at $44.5^{\circ} \mathrm{C}$ (APHA, 1992). Fecal coliforms are natural inhabitants of the gut of humans and other warm-blooded animals. They are present in water bodies contaminated with human and animal fecal waste. The contaminated water bodies serve as natural habitats

*Corresponding author. E-mail: sk_garg001@yahoo.com. Tel: +91-5278-247350. Fax: +91-5278-246330. of pathogenic coliforms, thereby playing a role in the disease process (Ademola et al., 2009). Water-borne potential pathogens such as E. coli 0157, Salmonella spp., Shigella spp. and Vibrio cholerae can lead to diarrhoeal outbreaks that may have serious medical implications (WHO, 2000). Recently, considerable concern has been expressed over the prevalence of multiple antibiotic resistant (MAR) bacteria in drinking water sources. The indiscriminate use and subsequent release of residual antibiotics in wastewater is considered an important factor for the emergence, selection and dissemination of antimicrobial resistant bacteria. The 
selective pressure for the antibiotic resistance is due to subsequent sub-therapeutic concentration of antibiotics in wastewater discharged into natural water bodies (Diwan et al., 2010) or selective pressure on natural organisms by antibiotics producing strains of bacteria and fungi in the environment (Allen et al., 2010). The residual antibiotics discharged from domestic, hospital, agriculture sources may find their way into various water bodies including rivers, ponds, etc, which may exert selective pressure (Kummerer, 2004). Microbial resistance to antibiotics and metal ions is a potential health hazard since these traits are generally associated with transmissible plasmids (Calomiris et al., 1984; Tripathi et al., 2011).

The heavy metals present in polluted water may adversely affect the plants, animals and humans. Heavy metals' resistance may be possibly due to extrusion of metal species, bioaccumulation, transformation, production of low molecular weight binding proteins, etc. (Silver and Misra, 1988). The survival of microorganisms in polluted environment depends on intrinsic biochemical, structural, physiological properties and/or genetic adaptation including morphological changes in the cells, as well as, environmental modification of metal speciation (Abskharon et al., 2008). The antibiotic resistance and heavy metal tolerance are associated phenomena in bacterial isolates from various metal-contaminated environments (Calomiris et al., 1984).

Bacterial resistance to antibiotics and heavy metals is an increasing problem in today's society. The dissemination of drug-resistance in bacteria is complicating the treatment of infections (Akturk et al., 2012). Much of the problems are as results of antibiotic resistance genes transferred among bacterial species via plasmids and transposons (Strokes and Hall, 1989). Resistance to antibiotics and heavy metals are acquired by a change in the genetic makeup of a bacterium, which can occur either by a genetic mutation or by transfer of resistant genes from bacteria in the environment (Kumar et al., 2011). Transmissibility of antibiotic resistance was demonstrated in $30-55.7 \%$ of MAR isolates (Gaur et al., 1992). Location of metal and drug resistance genes on a plasmid may be the result of independent insertions from mobile gene cassettes known as integrons. Although, resistance to metal ions is of less clinical concern than resistance to antibiotics, such association is significant as knowledge of metal ion tolerance may provide useful information on mechanism of antibiotic resistance, plasmid genetics, physiology and ecology of microorganisms in the polluted environment (Ramteke, 1997). Thermotolerant organisms were isolated from rural drinking water sources (piped supplies, hand pumps, tube wells, dug wells, ponds, lakes, and rivers Gomti and Ganges) from Lucknow and Kanpur districts of Uttar Pradesh. Kanpur is an industrially important city located on the bank of holy river Ganges and the industries directly release heavy metals through their effluents. The leaching and percolation of contaminated water may affect underground drinking water as well. Therefore, it was aimed through present study to evaluate linked transfer of antibiotic and metal resistance traits especially among multiple antibiotic resistant fecal coliforms using plasmid transfer and curing.

\section{MATERIALS AND METHODS}

\section{Sampling and isolation procedure}

Water samples were collected from villages of Lucknow and Kanpur districts (India). A total of 188 samples were analyzed for bacteriological quality of drinking water. The water samples were collected from 54 piped supplies, 51 hand pumps, 27 tube wells, 8 dug wells and 48 surface water sources (42 samples from rivers Gomti and Ganges, 2 ponds and 4 lakes). Water samples were collected in sterile glass bottles and transported to the laboratory on ice and processed within $6 \mathrm{~h}$ of collection. The most probable number (MPN) (APHA, 1992) method, $\mathrm{H}_{2} \mathrm{~S}$ strip test (Manja et al., 1982 ) and presence/absence (P-A) test (Clark, 1968) were employed to detect and isolate coliforms (APHA, 1992). Purified colonies were obtained by plating on MacConkey's agar (Hi-Media Pvt. Ltd, India). Microorganisms were identified as per the modified scheme of Chattopadhyay and Basu (1986). Further, the isolation of thermotolerant isolates was done by sub-culturing into Brilliant Green Bile Broth (BGBB) and peptone water at $44.5^{\circ} \mathrm{C}$. Gas production in $B G B B$ and indole formation in peptone water at $44.5^{\circ} \mathrm{C}$ was used for the detection of thermotolerant isolates after $48 \mathrm{~h}$ incubation.

\section{Antibiotic sensitivity and metal tolerance test}

Sensitivity to antibiotics was determined on Mueller-Hinton medium (Hi-media) containing antibiotics $\left(\mu \mathrm{g} \mathrm{ml}{ }^{-1}\right)$ : ampicillin (25), chloramphenicol (30), streptomycin (30), tetracycline (30), kanamycin (30), gentamycin (10), polymixin-B (50), cephaloridine (30), co-trimoxazole (25), nalidixic acid (30), carbenicillin (100), bacitracin (10), vancomycin (30), norfloxacin (20). All antibiotics were supplied by Hi-Media Laboratory Pvt. Ltd, Mumbai. Tolerance to metal ions was determined by minimal inhibitory concentration technique (Cervantes-vega et al., 1986). The metal salts used were arsenic oxide, cobalt nitrate, cadmium chloride, potassium dichromate, nickel chloride, zinc chloride, copper sulfate and mercuric chloride. Concentrations of metals were: $\mathrm{Zn}, \mathrm{Ni}, \mathrm{Cu}(400$ $\left.\mu \mathrm{g} \mathrm{ml}^{-1}\right), \mathrm{Cr}, \mathrm{Cd}$, Co, As $\left(100 \mu \mathrm{g} \mathrm{ml}^{-1}\right)$ and $\mathrm{Hg}\left(25 \mathrm{gg} \mathrm{ml}^{-1}\right)$.

\section{Resistance transfer}

A total of 24 thermotolerant coliforms representing different resistance patterns were tested for their ability to transfer resistances to $E$. coli $\mathrm{K} 12 \mathrm{~J} 62$ (lac', pro', his', trp-, $\mathrm{Nal}^{-}$) recipient strain (Walter and Vennes, 1985). Overnight grown cultures $(0.1 \mathrm{ml}$ each) were inoculated into $10 \mathrm{ml}$ brain heart infusion $(\mathrm{BHI})$ broth (HI-Media), incubated for $6 \mathrm{~h}$, then $0.1 \mathrm{ml}$ each of donor and recipient cultures were mixed and incubated for $18 \mathrm{~h}$ at $28^{\circ} \mathrm{C}$ for conjugation. Transconjugants were selected on MacConkey's agar containing nalidixic acid with appropriate antibiotic/heavy metal. To assess $\mathrm{R}$-factor transfer in sterile water, the donors and recipient were grown to mid log phase, pelleted by centrifugation (4000 rpm 


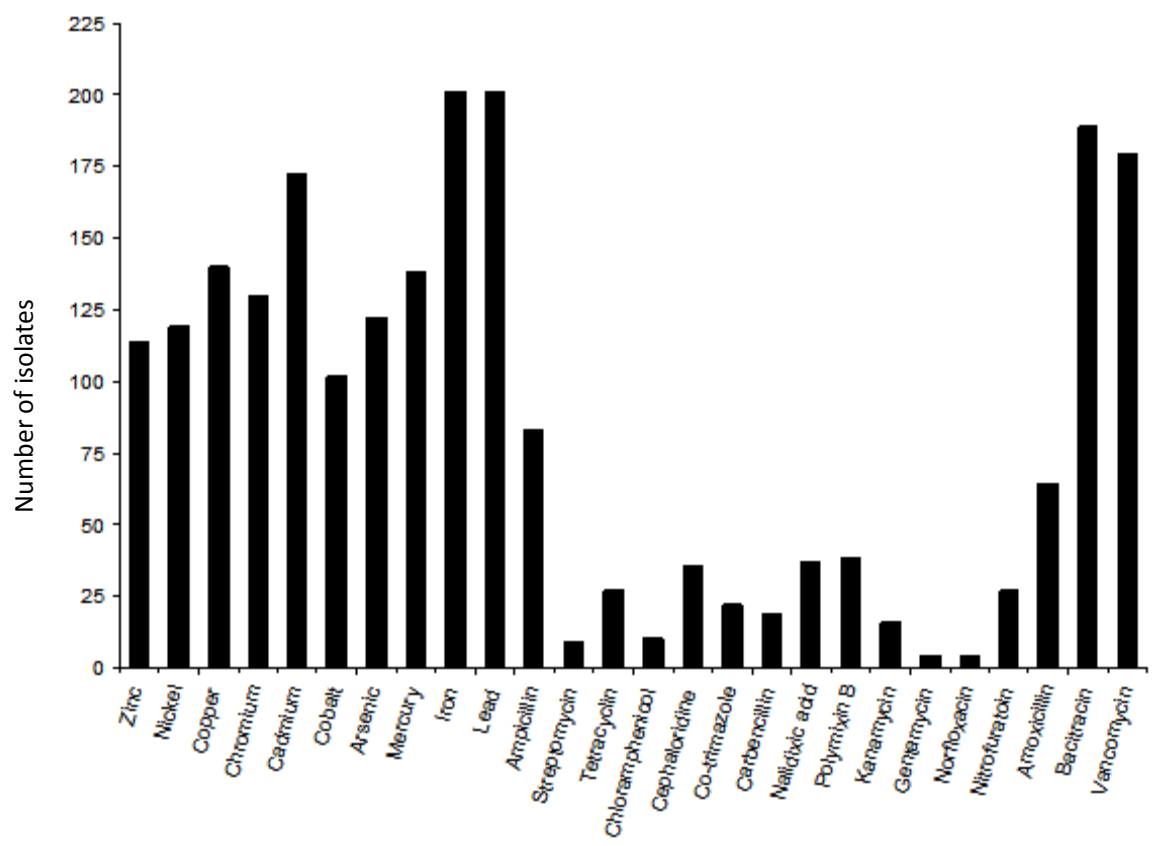

Heavy metals and antibiotics

Figure 1. Antibiotic resistance pattern and heavy metal tolerance among thermotolerant isolates.

for $30 \mathrm{~min}$ ) and finally suspended to the original volume. Mating was performed in sterile water at $26^{\circ} \mathrm{C}$ with or without shaking for $6 \mathrm{~h}$.

\section{Plasmid curing}

It was done using curing agent $\left(\mu \mathrm{g} \mathrm{ml}^{-1}\right)$ : acridine orange, 20; sodium dodecyl sulfate, $250-1000$ or rifampicin, $0.5-1.0$. Tubes containing $10 \mathrm{ml}$ peptone water were supplemented with the curing agent, inoculated with $0.1 \mathrm{ml}$ of overnight broth culture and incubated at $37^{\circ} \mathrm{C}$ for $24 \mathrm{~h}$. Appropriate dilutions of the culture were plated on nutrient agar to obtain single colony isolates after 24 $\mathrm{h}$ incubation at $37^{\circ} \mathrm{C}$. Resulting colonies were tested for loss of plasmid on nutrient agar plates incorporated with the appropriate antibiotic/metal ion.

\section{RESULTS AND DISCUSSION}

\section{Antibiotic resistance}

Thermotolerant isolates (201) from various drinking water sources were studied for antibiotic susceptibility test (Figure 1). Among them, 112 were coliforms and remaining 89 were non coliforms. All isolates were found predominantly resistant to bacitracin (93.9\%), vancomycin (89\%) followed by ampicillin $(41.2 \%)$. In moderate number of isolates, the resistance was observed for amoxicillin (31.5\%), polymixin-B (18.6\%) and cephaloridine (17.5\%). Low level of resistance was observed for tetracycline (13.6\%), nitrofurtoin (13.5\%), co-trimazole $(10.7 \%)$, carbencillin $(9.2 \%)$, kanamycin $(7.9 \%)$, chloramphenicol $(4.8 \%)$, streptomycin $(4.5 \%)$, norfloxacin $(1.8 \%)$ and gentamycin $(1.7 \%)$. The results indicated widespread occurrence of antibiotic resistance among thermotolerant isolates in drinking water sources. Predominant resistance to bacitracin and vancomycin was found among the isolates included in the study. Cent per cent resistance to bacitracin in fecal coliforms was also reported by Qureshi and Qureshi (1992). In our study, significant number of isolates (80, i.e. $41 \%$ ) was resistant to ampicillin, an antibiotic very commonly used for treatment now-a-days. The results are somewhat similar to those reported by other workers (Ramteke, 1997). The high incidence of ampicillin resistance may be due to production of $\beta$-lactamase by the bacterial strains, thereby nullifying the action of $\beta$-lactum family of antibiotics by opening the $\beta$-lactum ring in their molecular structure (Ramteke et al., 1992). The varying levels of resistance to antibiotics is supposed to be due to the presence of antibiotic at low concentrations in hospital/household wastewater finding its way to water bodies and underground water sources (Diwan et al., 2010).

\section{Multiple antibiotic resistance (MAR) among thermotolerant isolates}

The cultures which were resistant to more than two 
antibiotics were considered as multiple antibiotic resistant (MAR). Eighty four (41.8\%) thermotolerant isolates were found MAR. Resistance to single (1R) and double (2R) antibiotics were observed in $30(14.9 \%)$ and $72(35.9 \%)$ isolates, respectively. Fifteen $(7.4 \%)$ thermotolerant isolates were susceptible to all the antibiotics tested. The extensive use and abuse of antibiotics in human therapy has resulted in co-existence of multiple antibiotic resistant and sensitive bacteria together in the natural reservoirs. Prevalence of MAR isolates was also reported by other researchers in drinking water bodies (Gaur et al., 1992). Allen et al. (2010) argued that selection pressure because of indiscriminate use and release of antibiotics leads to evolution of MAR. However, existence of antibiotic resistant isolates during pre-antibiotic era has also been recorded (Diwan et al., 2010).

\section{Metal tolerance}

Heavy metal incidence has become a serious threat due to their indiscriminate release into the environment. Natural, as well as, anthropogenic sources account for this contamination, which is of great concern to the public health (Rathnayake et al., 2010). In this study, besides resistance to antibiotics, thermotolerant isolates were also tolerant to heavy metals and all isolates were resistant to $\mathrm{Pb}$ and $\mathrm{Fe}$. Majority of them were also tolerant to $\mathrm{Co}, \mathrm{Ni}, \mathrm{Cd}, \mathrm{Zn}, \mathrm{Hg}, \mathrm{Cu}, \mathrm{Cr}$ and As (Figure 1). The incidence of high level of metal tolerance among bacteria could be attributed to the release of metal ions in water bodies through the industrial effluents. Bacterial resistance to metal ions seems to be directly related to the presence and adaptive response to these elements in the environment (Timoney et al., 1978). In the present study, the isolates from sources supposed to be free from heavy metal contamination have also shown tolerance to heavy metals, as well as, resistance to antibiotics. Coexistence of antibiotic resistance and heavy metal tolerance traits in bacteria has also been reported by other researchers (Allen et al., 2010; Baker-Austin et al., 2006; Ghosh et al., 2000).

\section{Transfer of resistance to thermotolerant coliforms}

Twenty four strains of thermotolerant coliforms representing different resistance patterns were tested for plasmid transfer by conjugation. All nine MAR strains of above thermotolerant coliforms exhibited the ability to transfer their antibiotic resistance markers; bacitracin trait was transferred in all the nine MAR strains, whereas, in two strains ampicillin was also co-transferred with bacitracin trait. Thirteen strains showing resistance to two antibiotics (2R) transferred only one marker of bacitracin. Remaining two strains (out of 24 ) with resistance to one antibiotic (1R) also transferred only the trait for bacitracin. Summarily, the transfer of resistance to bacitracin was observed in all the 24 thermotolerant isolates, whereas resistance to ampicillin was transferred by only two isolates (Figure 2).

Several workers reported that $50-70 \%$ of MAR strains were capable of transferring their resistance markers (Walter and Vennes, 1985). Earlier studies in India reported an increasing trend of resistance transfer among thermotolerant coliforms (Gaur et al., 1992). In case of heavy metals, transfer was observed for $\mathrm{Ni}$ (8 isolates), $\mathrm{Cu}, \mathrm{Cd}$, Co (5 isolates), and $\mathrm{Zn}, \mathrm{Cr}$ (both 4 isolates). Highest transfer of resistance was observed for As (17 isolates) (Figure 2). Interestingly, transfer of resistance to $\mathrm{Hg}$ was not detected in the present study. Conjugation experiments were conducted in order to see the transfer of R-plasmid to sensitive population. The results of this study highlighted that all 24 thermotolerant coliforms studied for transfer of R-plasmid demonstrated the transfer of at least one resistant trait. This finding is slightly different from earlier reports of Gaur and coworkers (1992) who observed that only $15.3 \%$ organisms were able to transfer their resistance to $E$. coli $\mathrm{K} 12$ recipient.

\section{Linked transfer of resistance to antibiotics and heavy metals among thermotolerant coliforms}

Of the 24 coliforms studied, 12 (50\%) exhibited linked transfer of resistance. Linked transfer of B-As-Ni-Co was detected in $3(12.5 \%)$ strains, whereas, B-As transferred in $9(37.5 \%)$ strains. Ghosh et al. (2000) also reported about a transferable plasmids encoding resistance to various heavy metals and antibiotics in Salmonella abortus equi. The study indicated the linked transfer of antibiotic(s) and metal(s) especially among MAR isolates. The linked transfer may have serious public health implications. The sensitive isolates present in the drinking water may acquire resistance(s) borne on conjugative plasmids rendering them resistant, which will have an added advantage to adapt and survive in metal containing water systems.

\section{Curing of R-plasmid and its relationship with plasmid transfer among thermotolerant coliforms}

Thirty two cultures of thermotolerant coliforms were studied for curing of R-plasmid using acridine orange (Figure 2). Among the antibiotics, curing of resistance was observed for streptomycin (25\%), cephaloridine and kanamycin (both $50 \%$ ). Curing of resistance to ampicillin, bacitracin, chloramphenicol and polymixin- $B$ was not detected. High level curing of resistance to heavy metals such as $\mathrm{Ni}(90 \%)$, Co (90\%), $\mathrm{Hg}(75 \%), \mathrm{Cr}(75 \%)$, Cu 


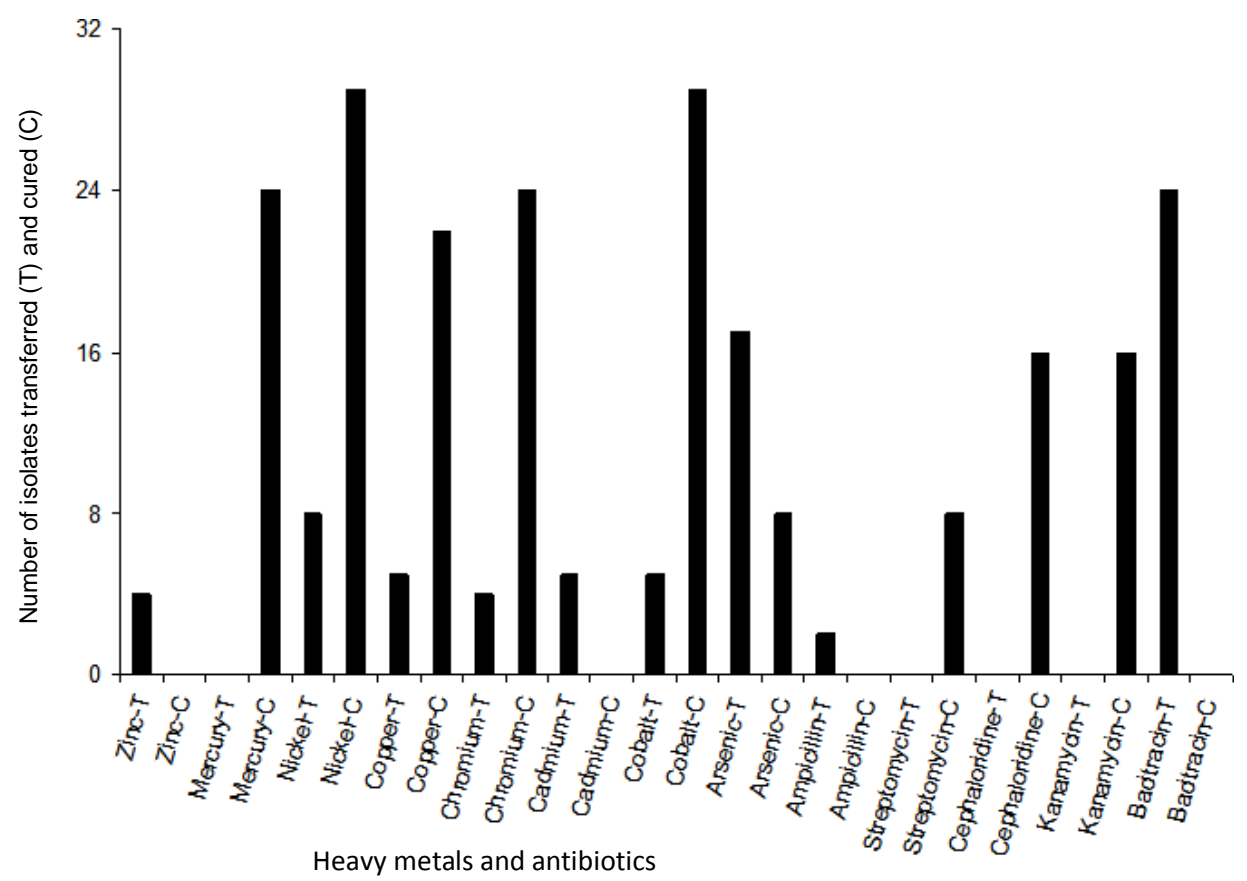

Figure 2. Relationship between R-plasmid transfer and curing among thermotolerant coliforms for heavy metals and antibiotics.

(68\%), and low level curing of resistance to As (27\%) was detected. Among thermotolerant coliforms, no correlation could be established between the ability to transfer the antibiotic resistance trait(s) and curing. The resistance traits for bacitracin and ampicillin were transferred but not cured. Conversely, resistance to streptomycin, cephaloridine and kanamycin was cured, but their transfer was not detected. The relationship between resistance to heavy metal(s) transfer and curing is shown in Figure 2. Resistance to $\mathrm{Zn}$ and $\mathrm{Cd}$ were transferred, whereas, their curing was not detected. Conversely, resistance to $\mathrm{Hg}$ was cured, but its transfer did not occur. However, the relationship between transfer and curing of resistance to $\mathrm{Ni}, \mathrm{Cu}, \mathrm{Cr}, \mathrm{Co}$ and $\mathrm{As}$ was established (Figure 2). Studies have suggested that antibiotic and metal resistance is frequently associated with plasmids (Foster, 1983).

The present study revealed that acridine orange was able to eliminate resistance, but resistance pattern of the individual strains did not influence the percentage of cells cured. It was suggested by Singh and Yadav (1988) that, it is the characteristic of the plasmid, which determines the curing frequencies. Although, loss of antibiotic resistance on exposure to acridine was demonstrated, no relationship was evident between the strains exhibiting transfer of antibiotic resistance and those strains undergoing plasmid curing. In all the strains studied for transfer of resistance among antibiotics, bacitracin was transferred but was not cured by acridine orange.
However, plasmid borne characteristic of resistance was evident by their curing. Further studies should be conducted on the treatment necessary for drinking water when antibiotic resistant bacteria are present. Piped supplies and dug wells have been reported as the common sources of enteric pathogens resistant to antibiotics and heavy metals. Linked transfer of antibiotic resistance and heavy metal tolerance traits is attributed to the presence of R-plasmid. The bacteria carrying Rplasmid have greater chances of propagation in natural ecosystems compared to strains lacking plasmids (Grabow et al., 1975). This necessitates limiting the dissemination of $\mathrm{R}$-bacteria in drinking water sources in order to protect human population against the hazard of infection.

Antibiotic resistance in bacteria is a serious threat to society today, and one of the reasons responsible for this problem is overuse of antibiotics in humans (Okeke et al., 2007). According to Sayah et al. (2005), the source of water contamination plays significant role in determining the extent of antimicrobial resistance as contaminating bacteria could come from domestic, wild animals' or human sewage. Antibiotic resistance poses a threat to everyone, especially the children and the immunocompromised, who are more vulnerable to bacterial illnesses. For the general public as a whole, antibiotic resistance limits the number of effective drugs available leading to fewer treatment options for the sick.

Surveillance of the prevalence of MAR thermotolerant 
coliforms and the potential public health hazards associated with spread of MAR bacteria in the environment, sewage and drinking water should not be overlooked in the tropics where sanitation is limited and there are serious constraints in the provision of adequate water treatment. The present study emphasizes need for a surveillance system designed to identify and define important factors in the emergence, persistence and transmission of drug resistant bacteria in the environment. Therefore, the need for a surveillance system that can clearly delineate the extent of problematic resistant bacteria in drinking water is imperative.

\section{Conclusions}

The incidence of high level metal tolerance among thermotolerant coliforms could be attributed to the release of metal ions in water bodies through the industrial effluents. Our study revealed that the metal tolerance and antibiotic resistance traits are conjugative plasmid borne, as they could be transferred to sensitive strains through the conjugation process. The presence of resistance traits on plasmids was also evident from curing experiments. The present study clearly indicates the linked transfer of antibiotic and metal resistance traits especially among multiple antibiotic resistant microorganisms. It is, therefore, suggested that release and dissemination of resistant microbial population in the water bodies and indiscriminate uses of antibiotics should be prohibited. Adequate steps should be taken for complete disinfection and treatment of drinking water sources.

\section{ACKNOWLEDGEMENTS}

The authors would like to thank the Director, Indian Institute of Toxicological Research, Lucknow, for his constant encouragement. Sincere thanks also to Institute of Microbial Technology, Chandigarh for providing E. coli K12J62 strain.

\section{REFERENCES}

Abskharon RN, Hassan SH, Gad E1-Rab SM, Shoreit AA (2008). Heavy metal resistant of $E$. coli isolated from wastewater sites in Assiut City, Egypt. Bull. Environ. Contam. Toxicol. 81(3):309-315.

Ademola O, Olaniran KN, Balakrishna P (2009). Antibiotic resistance profile of Escherichia coli isolates from river sources in Durban, South Africa. World J. Microbiol. Biotechnol. 25(10):1743-1749.

Akturk S, Dincer S, Toroglu S (2012). Determination of microbial quality and plasmid-mediated multidrug resistant bacteria in fountain drinking water sources in Turkey. J. Environ. Biol. 33:1127-1136.

Allen HK, Donato J, Wang HH, Cloud-Hansen KA, Davies J, Handelsman J (2010). Call of the wild: antibiotic resistance genes in natural environments. Nat. Rev. Microbiol. 8:251-259.

APHA (1992). Standard methods for examination of water and wastewaters, Washington, DC.

Baker-Austin C, Wright MS, Stepanauskas R, McArthur JV (2006). Coselection of antibiotic and metal resistance. Trends Microbiol. 14(4):176-182.

Calomiris JJ, Armstrong JL, Seidler RJ (1984) Association of metal tolerance with multiple antibiotic resistance of bacteria isolated from drinking water. Appl. Environ. Microbiol. 47:1238-1242.

Cervantes-vega C, Chanez J, Cordona NA, de la Mora P, Velasco JA (1986). Resistance to metals by Pseudomonas aeruginosa clinical isolates. Microbios 4(196-197):159-163.

Chattopadhyay D, Basu S (1986). Modified scheme for identification of coliform organisms in drinking water. Indian J. Med. Res. 83:152-154.

Clark JA (1968). A Presence-Absence (P-A) test providing sensitive and inexpensive detection of coliforms, faecal coliforms and faecal streptococci in municipal drinking water supplies. Can. J. Microbiol. 14(1):13-18.

Diwan V, Tamhankar AJ, Khandal RK, Sen S, Aggarwal M, Marothi Y, lyer RV, Sundblad-Tonderski K, Stalskby-Lundborg C (2010) Antibiotics and antibiotic-resistant bacteria in waters associated with a hospital Ujjain, India. BMC Public Health 10:414.

Foster TJ (1983). Plasmid determined resistance to antimicrobial drugs and toxic metal ions in bacteria. Microbiol. Rev. 47(3):361-409.

Gaur A, Ramteke PW, Pathak SP, Bhattacharjee JW (1992). Transferable antibiotic resistance among thermotolerant coliforms from rural drinking water in India. Epidemiol. Infect. 109(1):113-120.

Ghosh A, Singh A, Ramteke P, Singh V (2000). Characterization of large plasmids encoding resistance to toxic heavy metals in Salmonella abortus equi. Biochem. Biophys. Res. Commun. 272:611.

Grabow WOK, Prozesky OW, Burger JS (1975). Behavior in a river and dam of coliform bacteria with transferable or non-transferable drug resistance. Water Res. 9:777-782.

Kumar PA, Joseph B, Patterson J (2011). Antibiotic and heavy metal resistance profile of pathogens isolated from infected fish in Tuticorin, south-east coast of India. Indian J. Fish. 58(2):121-125.

Kummerer K (2004). Resistance in the environment. J. Antimicrob. Chemother. 54:311-320.

Manja KS, Maurya MS, Rao KM (1982). A simple field test for the detection of faecal pollution in drinking water. Bull. World Health Organ. 60(5):797-801

Okeke IN, Abiodun OA, Byarugaba DK, Ojo KK, Opintan JA (2007). Growing problem of multidrug-resistant enteric pathogens in Africa. Emerg. Infect. Dis. 13(11):1640-1646.

Qureshi AA, Qureshi MA (1992). Multiple antibiotic resistant fecal coliforms in raw sewage. Water Air Soil Pollut. 61(1-2):47-56.

Ramteke PW (1997). Plasmid mediated co-transfer of antibiotic resistance and heavy metal tolerance in coliforms. Indian J. Microbiol. 37:177-181.

Ramteke PW, Bhattacherjee JW, Pathak SP, Kalra N (1992). Evaluation of coliforms as indicators of water quality in India. J. Appl. Bacteriol. 72(4):352-355.

Rathnayake IVN, Megharaj M, Bolan N, Naidu R (2010). Tolerance of heavy metals by Gram positive soil bacteria. Int. J. Civil Environ. Eng. 2(4):191-195.

Sayah RS, Kaneene JB, Johnson Y, Miller RA (2005). Patterns of antimicrobial resistance observed in Escherichia coli isolates obtained from domestic- wild-animal fecal samples, human septage, and surface water. Appl. Environ. Microbiol. 71(3):1394-1404.

Silver S, Misra TK (1988) Plasmid mediated heavy metal resistances. Ann. Rev. Microbiol. 42:717-743.

Singh M, Yadav JNS (1988). Effect of acridium ions on curing on R plasmid. Indian J. Exp. Biol. 26(10):668-670.

Strokes HM, Hall RM (1989). A novel family of potentially mobile DNA elements encoding site-specific gene-integration functions. Mol. Microbiol. 3:1669-1683.

Timoney JF, Port J, Giles J, Spanier J (1978). Heavy metal and antibiotic resistance in the bacterial flora of sediments of New York Bight. Appl. Environ. Microbiol. 36:465-472. 
Tripathi M, Vikram S, Jain RK, Garg SK (2011). Isolation and growth characteristics of chromium (VI) and pentachlorophenol tolerant bacterial isolate from treated tannery effluent for its possible use in simultaneous bioremediation. Indian J. Microbiol. 51(1):61-69.
Walter MV, Vennes JW (1985). Occurrence of multiple antibiotic resistant enteric bacteria in domestic sewage and oxidation lagoons. Appl. Environ. Microbiol. 50(4):930-933. 